\title{
An Insight into Oil and Grease Removal from Wastewater from Petroleum and Refinery Industries
}

\author{
Sunil Jayant Kulkarni \\ Datta Meghe College of Engineering, \\ Airoli, Navi Mumbai, Maharashtra, India \\ suniljayantkulkarni@gmail.com
}

\begin{abstract}
Wastewater treatment for removal of organic matter, inorganic matter and heavy metals is becoming increasingly important area of research. The disposal of wastewater to sea and other reservoirs can cause serious environmental problems. Wastewater from petroleum and refineries contains organic matter in various forms. Biodegradable and nonbiodegradable pollutants call for different biological and physical treatments for wastewater. The presence of oil and grease causes different problems including health effects. They also have adverse effects on treatability. The present review presents an insight into treatment technologies used for oil and grease removal from wastewater.
\end{abstract}

Keywords: Chemical oxygen demand, organic matter, parameters, concentration.

\section{INTRODUCTION}

Wastewater treatment is important aspect of investigations to meet objective of sustainable development and clean technology. The wastewater contains organic and inorganic matter. The organic matter present in the wastewater is measured as chemical oxygen demand (COD) and biological oxygen demand (BOD). The COD to BOD ratio is important factor in deciding the treatment method. The organic matter from industrial wastewater can be removed by various physical, chemical and biological methods $[1,2,3,4,5]$. Biological treatment includes activated sludge process (ASP), advance oxidation, anaerobic reactors, membrane bioreactor and trickling filter $[6,7,8]$. The physic-chemical treatments like adsorption, electrostatic seperators are also effective for removal of organic matter from petrochemical wastewater $[9,10]$. The petroleum waste contains oil and grease in addition to other pollutants like phenol and other organic compounds. Various methods like adsorption, extraction, floatation can be used for oil and grease removal from wastewater. The present review provides an insight into research and studies carried out for the treatment of petroleum and refinery wastewater.

\section{Research and Studies on Petroleum Wastewater Treatment}

Alade et.al.carried out investigation on oiland grease removal from industrial wastewater [11]. Refineries are sources of oil and grease in wastewater. They discussed various aspects of different treatment methods like flotation, gravitational methods, chemical treatment, biological treatment, dissolved air flotation (DAF) and use of membranes. According to them, these methods are not efficient for finely dispersed droplets. According to them oil droplets of $50 \mu \mathrm{m}$ ca be removed by API separators, Corrugated Plate Interceptors (CPI), and Parallel Plate Interceptors (PPI). Kulkarni and Goswami carried out studies on wastewater treatment in petroleum industry [12]. According to them, image analysis is powerful tool for characterization oil droplet sizes in oily wastewater. Lamella separator can be used for oil and water separation before treating it biologically. The oil and grease present in the wastewater must be removed before it is send to biological treatment processes as it can affect the biological activity and oxygen exchange. Pawlak et.al. Discussed various pathways through which the oil and grease enters into water[13]. Their results indicated that total petroleum hydrocarbon fraction (TPH) accounted for oil and grease $(\mathrm{O} / \mathrm{G})$ and the ratio of $[\mathrm{TPH}] /[\mathrm{O} / \mathrm{G}]$ ranged from $12 \%$ to $50 \%$. Megid et.al. carried out an investigation on treatment of oil-water emulsion[14].In their work, they optimized coagulation and flotation processes to reduce the concentrations of oil, grease and other contaminants using different coagulants. They used coagulating agents like alum, ferrous sulphate, ferric chloride. Ferrous sulphate, alum and ferric sulphate were able to remove the 
oil content by $67 \%, 73 \%$ and $74 \%$ respectively with $\mathrm{pH} 10,10$ and 8 respectively. They also found that, dissolved air flotation technique was very effective secondary treatment method for treating refinery wastewaters.

Igunnu and Chen discussed produced water treatment technology[15]. They evaluated current technologies for the management of produced water. They studied the importance of electrochemical technology to treat this water. Produced water contains various organic and inorganic impurities. They discussed various treatment technologies used in produced water treatment such as membrane filtration technology, thermal technologies, biological aerated filters, electrodialysis/electrodialysis reversal, freeze thaw evaporation etc. According to these studies two key drawbacks of membrane technologies are membrane fouling and secondary waste generation. According to the authors, macroporous polymer extraction technology (MPPPE) technology can compete in the future management of produced water. It has potential to reduce the discharge to zero. Naggar carried out investigation on used of petroleum cuts as solvent for treatment of waste sludge [16]. They investigated effect of various factors like shaking time, temperature and the solvent volume upon oil recovery. They found that the maximum oil recovery obtained varied from $80-97 \%$ depending upon the amount of oil within the sludge and the solvent efficiency used for extraction. They also studied various factors affecting the process such as solvent sludge ratio, temperature and shaking time. Hayes et.al. carried out review on various treatment technologies used in the treatment of produced water [17]. They presented results of integrated electrodialysis pilot unit. By using this technology it was possible to remove 99.5 percent of oil and grease from effluent. According to these studies, processes like API separator, deep bed filter, hydro cyclone, induced gas flotation and ultra-filtration have the potential to remove oil from effluent. Martinez-Delgadillo et.al. studied the electro coagulation treatment to remove pollutants from petroleum refinery wastewater[18]. According to these studies, the iron electrodes have better performance compared to aluminum electrodes. They observed that removal of COD and oil followed first order kinetics. Asia et.al. carried out studies on treatment of petroleum industry wastewater[19]. They characterized the effluent and determined various characteristics of petroleum effluent. They determined the parameters like solids concentration, $\mathrm{pH}$, temperature, biochemical oxygen demand, chemical oxygen demand, dissolved oxygen, phosphate, nitrogen, conductivity, calcium, magnesium, sodium, potassium, iron, manganese, lead and chromium. They found that the values of most of these parameters were above the limit of World Health Organization (WHO) standards. The COD to BOD ratio of 2.6 indicated that the sludge is biodegradable. Igwe et.al. studied various options available for offshore produced water treatment[20]. The trapped water from the underground areas comes to the surface during petroleum exploration. This water contains oil and grease. This water needs to be treated for removal of various pollutants including oil and grease. They discussed the conventional treatment technologies such as adsorption, membrane separation, ion exchange etc. for the effluent treatment. According to these studies, characterization of the wastewater is important aspect of the treatment procedure. The results of this characterization and analysis are deciding factor for selection of the appropriate treatment method. Helmy and Kardena studied various treatment methods for treatment of waste from petroleum oil and gas industry[21]. Almost $85 \%$ removal total petroleum hydrocarbon (TPH) of oil and grease can be accomplished by using bioemulsifier. Benyahia et.al. studied the refinery wastewater treatment[22]. He developed biomass extraction treatment technology. According to them, there is need to upgrade the existing treatment units in order to meet the regulatory norms.

\section{Conclusion}

Proper characterization of the wastewater is needed for selection of the treatment method. COD to BOD ratio is deciding factor most of the times in selection of treatment methods. Various methods available for treatment of petroleum and refinery wastewater include floatation, coagulation, adsorption and electrostatic separation. Oil and grease removal can be carried out by these methods. Also some inertial separators and gravity separators can be used for oil and grease removal from wastewater

\section{REFERENCES}

[1] Pallavi Amale, Sunil Kulkarni, Kavita Kulkarni (2014), “A review on research for industrial wastewater treatment with special Emphasis on distillery effluent", International Journal of Ethics in Engineering \& Management Education, 1(9), PP.1-4. 
[2] Khantong Soontarapa and Nuntachai Srinapawong(2001), "Combined membrane-trickling filter waste water treatment system”, J. Sci. Res. Chula. Univ., 26(2), PP. 59-71.

[3] Dinesh Mohan, Kunwar P. Singh, Vinod K. Singh(2008), "Wastewater treatment using low cost activated carbons derived from agricultural byproducts-A case study", Journal of Hazardous Materials, 152(3), PP.2045-1053.

[4] Sunil J. Kulkarni, Ajaygiri K. Goswami(2014), “Applications and Advancements in Treatment of Waste Water by Membrane Technology- A Review", International Journal of Engineering Sciences and Research Technology, 3(9), PP.446-450.

[5] Sunil J. Kulkarni(2014), "Modeling for Adsorption Columns for Wastewater Treatment: a Review", International Journal of Innovative Research in Engineering \& Multidisciplinary Physical Sciences (IJIRMPS), 2(2), PP.7-11.

[6] Jain Jyoti, Dubey Alka and Singh Jitendra Kumar(2013), "Application Of Membrane-BioReactor In Waste-Water Treatment: A Review", International Journal of Chemistry and Chemical Engineering. , 3(2), PP. 115-122.

[7] Sonali R. Dhokpande, Sunil J. Kulkarni, Dr. Jayant P. Kaware(2014), “A review on research on application of trickling filters in removal of various pollutants from effluent",International Journal Of Engineering Sciences \& Research Technology, 3(7), PP. 359-365.

[8] H.A. Gasim, S.R.M. Kutty, M. Hasnain Isa and L.T. Alemu(2013),"Optimization of Anaerobic Treatment of Petroleum Refinery Wastewater Using Artificial Neural Networks", Research Journal of Applied Sciences, Engineering and Technology, 6(11), PP.2077-2082.

[9] Basheer Hasan Diya'Uddeen, Wan Mohd Ashri Wan Daud, A.R. Abdul Aziz(2011), "Treatment technologies for petroleum refinery effluents:A review", Process Safety and Environmental Protection, 89, PP. 95-105.

[10] E-S.Z. El-Ashtoukhy, Y.A.El-Taweel, O. Abdelwahab, E.M.Nassef(2013), "Treatment of Petrochemical Wastewater Containing Phenolic Compounds by Electrocoagulation Using a Fixed Bed Electrochemical Reactor", Int. J. Electrochem. Sci., PP. 1534 - 1550, 2013.

[11] Abass O. Alade, Ahmad T. Jameel, Suleyman A. Muyubi,Mohamed I. Abdul Karim And Md. Zahangir Alam(2011), "Removal Of Oil And Grease As Emerging Pollutants Of Concern (Epc) In Wastewater Stream”, Iium Engineering Journal, 12(4), PP.161-170.

[12] Sunil Jayant Kulkarni, Ajaygiri Kamalgiri Goswami(2015), “A Review On Wastewater Treatment For Petroleum Industries And Refineries", Int. Journal On Scientific Research In Science, Engineering And Technology, 1(3), PP.280-283.

[13] Z. Pawlak A,B., T. Rauckyte A, A. Oloyede(2008), "Oil, Grease And Used Petroleum Oil Management And Environmental Economic Issues", Journal Of Achievements In Materials And Manufacturing Engineering, 26(1), PP.11-17.

[14] Mohamed Hussein Abdel Megid, Amer Abdel Razek Amer, Khaled Hassan Elsayed(2014), "Coagulation And Dissolved Air Floatation For Treatment Of Oil-Water Emulsion", Int. J. Eng. Sci., 3(12), PP. 120-129.

[15] Ebenezer T. Igunnu And George Z. Chen(2012),"Produced Water Treatment Technologies", International Journal Of Low-Carbon Technologies, Oxford University Press, PP.1-21.

[16] A. Y. El Naggar, E. A. Saad, A. T. Kandil and H. O. Elmoher(2010), "Petroleum Cuts As Solvent Extractor For Oil Recovery From Petroleum Sludge", Journal of Petroleum Technology and Alternative Fuels , 1(1), PP. 10-19.

[17] Tom Hayes, Dan Arthur(2004), "Overview Of Emerging Produced Water Treatment Technologies", The 11th Annual International Petroleum Environmental Conference Albuquerque Hilton Hotel Albuquerque, NM , October 12-15, PP.1-36.

[18] Sergio A. Martínez-Delgadillo, Miguel A. Morales-Mora and Icela D. Barcelo-Quintal(2010), "Electrocoagulation Treatment To Remove Pollutants From Petroleum Refinery Wastewater", Sustain. Environ. Res., 20(4), PP.227-231.

[19] Asia, I. O., Enweani, I. B. and Eguavoen I. O.(2006), "Characterization And Treatment Of Sludge From The Petroleum Industry", African Journal of Biotechnology,5(5), PP. 461-466.

[20] Onyems Igwe, Abdulrahman AL Saadi and Stanley E Ngene(2013), "Optimal Options for Treatment of Produced Water in Offshore Petroleum Platforms", J Pollut. Eff. Cont.,1(1), PP.15. 
[21] Qomarudin Helmy and Edwan Kardena(2015), "Petroleum Oil and Gas Industry Waste Treatment; Common Practice in Indonesia", J Pet Environ Biotechnol., 6(5), PP.1-7.

[22] Farid Benyahia, Refinery Wastewater Treatment: A true Technological Challenge, The Seventh Annual U.A.E. University Research Conference.

\section{AUTHOR'S BIOGRAPHY}

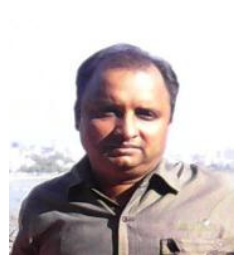

Mr. Sunil J. Kulkarni, has completed his Masters in Chemical Engineering from Tatyasaheb Kore Institute of Engineering and Technology, Warananagar in 2006. He is currently pursuing his phD in chemical engineering. He is working as Assistant Professor in Chemical Engineering Department of Datta Meghe College of Engineering, Airoli, Navi Mumbai, India. The author has 16 years of experience in teaching and research. He has published 113 international review and research papers and presented 15 research papers in international conferences. His area of research includes adsorption, environmental engineering and catalysis. He is editorial board member of more than 25 international journals and reviewed many international papers. 